\title{
NUTRITION IN SURGICAL PATIENTS; \\ ROLE OF PARTIAL PARENTERAL NUTRITRITION AND TOTAL PARENTERAL NUTRITION IN IMMEDIATE POST OPERATIVE PERIOD
}

1. Assistant Professor of Surgery Nishtar Medical College Multan.

2. Senior Registrar Surgery Nishtar Hospital Multan.

3. Consultant Surgeon Ghazi Khan Teaching Hospital DG Khan.

4. Professor of Surgery

Nishtar Medical College Multan.

Correspondence Address:

Dr. Tariq Jamil Choudhary

Senior Registrar Surgery

Nishtar Hospital Multan.

drtariqch@hotmail.com

Article received on:

24/10/2016

Accepted for publication:

05/01/2017

Received after proof reading:

$07 / 03 / 2017$

\section{Dr. Muzaffar Aziz', Dr. Tariq Jamil Choudhary², Dr. Muhammad Shafiq ${ }^{3}$, Dr. Khalid Hussain Qureshi ${ }^{4}$}

ABSTRACT... Objectives: The objective of this study was to compare the frequency of complications in postoperative patients with partial parenteral nutrition and total parenteral nutrition in surgical wards. Study design: Randomized Controlled Trial. Setting: Department of General Surgery of Nishtar Hospital Multan. Subjects \& Methodology: In this study, sixty patients of either gender with any abdominal surgery like primary repair of enteric perforation and repair of duodenal ulcer perforation were eligible for this study. In PPN group patients were given dextrose $10 \%$ in Ringer lactate solution just for 4 days. In TPN group patients got TPN solution that has $25 \mathrm{kcal} / \mathrm{kg}$ consistently for 4 days. All supplement preparations were prepared day by day under aseptic conditions. Infusion was performed through a central venous catheter using an injection micro pump. Information was gathered with respect to expanded hospital stay (> 7 days) and wound infection. Results: Age range in this study was from 20 to 40 years with mean age of $31.333 \pm 3.67$ years in PPN group while $32.200 \pm 3.87$ years in TPN group. Wound Infection was seen $50 \%$ in PPN group as compare to $10 \%$ in TPN group $(P=0.000)$ while Increased Hospital Stay was seen $26.7 \%$ in PPN group as compare to $6.7 \%$ in TPN group $(P=0.037)$. Conclusion: $P N$ feeding does not appear to offer beneficial advantage in rates of complications and it doesn't seem to diminish the length of hospital stay. TPN instantly taking after major surgery is a reasonable parenteral feeding.

Key words: $\quad$ Partial parenteral nutrition, Total parenteral nutrition, Complications

Article Citation: Aziz M, Choudhary TJ, Shafiq M, Qureshi KH. Nutrition in surgical patients; role of partial parenteral nutritrition and total parenteral nutrition in immediate post operative period. Professional Med J 2017;24(3):441-444.

DOI: $10.17957 / T P M J / 17.3693$

\section{INTRODUCTION}

In current surgical practice it is prudent to oversee patients inside an upgraded recohave them eating normal meal within 1-3 days. Thus, there is no place for routine perioperative nourishment. Just a minority of patients may get benefited by such treatment. These are dominatingly patients who are at danger of developing complications after surgery, in particular patients who have endured generous weight reduction, have low body mass record (BMI) (under 18.5-22 kg/m2 relying upon age) or show incendiary activity. ${ }^{1}$ Once patients have infectious complications, nutritious support is by and large required. It is troublesome, ethically unacceptable, to randomize this subgroup into those that do or don't get dietary support.

The primary objectives of perioperative dietary support are to minimize negative protein adjust by keeping away from starvation, with the reason for looking after muscle, insusceptible, and intellectual capacity and to improve postoperative recovery. ${ }^{2}$ About $8-38 \%$ of recently hospitalized patients are malnourished and turn out to be more malnourished amid healing center stay. ${ }^{3}$ Nutritional support is regularly given by means of the oral, enteral or parenteral route.

At whatever point conceivable, a patient's gastrointestinal tract is used for oral or enteral input, with parenteral nutrition (PN) held for patients with a non-working gastrointestinal tract. $\mathrm{PN}$ is a critical adjunctive nourishing treatment and comprises of complex blends of macronutrients and micronutrients. The many-sided quality of PN has brought about the improvement of numerous metabolic, mechanical and septic complexities, which are connected with increments in both 
mortality and morbidity. Partial parenteral nutrition (PPN) is a supplemental type of food conveyed intravenously to patients. Glucose, amino acids, salts, lipids, and vitamins are joined in differing sums in the PPN to meet the patient's specific needs. Entanglements from utilizing fractional parenteral nourishment incorporate electrolyte and liquid irregularity, high blood sugars, and disease. These inconveniences are minimized by running blood tests, watching strict sterile conventions, and restricting the time spent on PPN. The administration of total parenteral nutrition (TPN) can obviously keep the impacts of starvation in patients with a nonfunctioning gastrointestinal tract. Be that as it may, it is hazy whether TPN can balance the catabolic reaction to surgical stretch and decrease confusions related with hypercatabolism. ${ }^{4}$ Put in an unexpected way, the administration of total parenteral nutrition TPN may bring about noteworthy change in weight, nitrogen adjust, prealbumin levels and other healthful end focuses, yet the impact on clinically vital end focuses, for example, mortality and morbidity, is less sure. The purpose of this study was to compare the frequency of complications in term of wound infection and increased hospital stay in postoperative patients with partial parenteral nutrition and total parenteral nutrition in surgical wards of Nishtar Hospital Multan.

\section{MATERIAL AND METHODS}

This randomized controlled trial was conducted in department of general surgery of Nishtar Hospital Multan. Sixty patients of either gender with any abdominal surgery like primary repair of enteric perforation and repair of duodenal ulcer perforation were eligible for this study. Patients with history of diabetes, hypertension and renal disease were excluded. At the end of surgery, patients were randomized in the operating room using a sealed envelope to either PPN (Partial Parenteral Nutrition) or TPN (Total Parenteral Nutrition) group.

In PPN group patients were given dextrose 10\% and Ringer lactate solution just for 4 days. In TPN group patients got TPN solution that has 25 $\mathrm{kcal} / \mathrm{kg}$ consistently for 4 days. The proportion of glucose to lipid in this arrangement was 2:1, and nonprotein calorie to nitrogen $(\mathrm{kcal} / \mathrm{kg}$ ) was 100:1. Multivitamins, electrolytes, trace elements and insulin were additionally incorporated into the TPN solution. Strict aseptic conditions was ensured. Infusion was performed through a central venous catheter using an injection micro pump. Information was gathered with respect to expanded hospital stay ( $>7$ days) and wound infection.

Data was analyzed with statistical analysis program (SPSS version 20). Analysis was done to compare proportion (like age groups, gender) of PPN Group and TPN group. Frequency and percentage was computed for qualitative variables like age groups, gender, wound infection and increased hospital stay. Chi-square test was applied to compare outcomes in both groups taken $p \leq 0.05$ as significant

\section{RESULTS}

Age range in this study was from 20 to 40 years with mean age of $31.333 \pm 3.67$ years in PPN group while $32.200 \pm 3.87$ years in TPN group. Majority of patients were male in both groups as shown in Table-l.

\begin{tabular}{|l|c|c|}
\hline \multicolumn{1}{|c|}{ Demographics } & $\begin{array}{c}\text { PPN } \\
\mathbf{n ( \% )}\end{array}$ & $\begin{array}{r}\text { TPN } \\
\mathbf{n ( \% )}\end{array}$ \\
\hline Male & $25(83.3 \%)$ & $21(70 \%)$ \\
\hline Female & $5(16.7 \%)$ & $9(30 \%)$ \\
\hline $\begin{array}{l}\text { Repair of duodenal ulcer } \\
\text { perforation }\end{array}$ & $14(46.7 \%)$ & $9(30 \%)$ \\
\hline Repair of enteric perforation & $16(53.3 \%)$ & $21(70 \%)$ \\
\hline \multicolumn{2}{|l|}{ Table-I. Basic Demographics n=30 } \\
\hline \multicolumn{2}{|l|}{} \\
\hline
\end{tabular}

Wound Infection was seen $50 \%$ in PPN group as compare to $10 \%$ in TPN group $(P=0.000)$ while Increased Hospital Stay was seen $26.7 \%$ in PPN group as compare to $6.7 \%$ in TPN group $(P=0.037)$ as shown in Table-ll.

\begin{tabular}{|l|c|c|c|}
\hline \multicolumn{1}{|c|}{ Outcomes } & $\begin{array}{c}\text { PPN } \\
\mathbf{n}(\%)\end{array}$ & $\begin{array}{c}\text { TPN } \\
\mathbf{n}(\%)\end{array}$ & P value \\
\hline Wound Infection & $15(50 \%)$ & $3(10 \%)$ & 0.000 \\
\hline Increased Hospital Stay & $8(26.7 \%)$ & $2(6.7 \%)$ & 0.037 \\
\hline \multicolumn{2}{|c|}{ Table-II. Comparison of outcomes in both groups } \\
n=60
\end{tabular}




\section{DISCUSSION}

Well-nourished patients react to, and recuperate from disease and surgery superior to undernourished patients. Studies demonstrate that $30-40 \%$ of patients show poor nourishment on admission to doctor's facility and that both normal and sub-optimal nutritional status deteriorate in hospital. ${ }^{5}$ The physiological and psychosocial burdens of surgery increment the danger of poor nutritious status, which is obviously connected to poorer outcomes. ${ }^{6,7}$ Poor nutrition has clinical, economical and personal satisfaction consequences. ${ }^{7}$ Positive results for surgery depend intensely on adequate immune defense and wound healing. Both depend on improved blend of new proteins, which is altogether constrained by negative nitrogen and vitality adjust. A key point is that positive nitrogen adjust (net protein synthesis) can't be accomplished with negative energy balance. Semi-starvation will come within days as compare to weeks, when intake neglects to meet requirements, especially for protein and energy. In this study wound Infection was seen $50 \%$ in PPN group as compare to $10 \%$ in TPN group $(P=0.000)$ while increased hospital stay was seen $26.7 \%$ in PPN group as compare to $6.7 \%$ in TPN group $(P=0.037)$. The most well-known issue identified with pharmaceutical preparation of PN definitions is everyday changes of patients' requirement following change in their clinical and physiological conditions. ${ }^{8-11}$ Enhancing the nature of patients' metabolic backings can be accomplished with sufficient nutritious evaluation utilizing a standard convention. This is particularly critical in the settings, for example, a referral teaching hospital with high prevalence of nutritional support complexities. ${ }^{12}$ The ASPEN principles for nutritional support, suggest that all patients who are possibility for PN should undergo nutritional assessment at baseline before initiation of metabolic support. Baseline nutritional assessments incorporate social affair of patients' demographic information, for example, age, sex, weight, stature, dietary history, physical examinations including anthropometric data, and biochemical parameters. These estimations can be utilized to separate amongst intense and perpetual ailing health and figuring of patients' dietary prerequisites. These measurements were done to some degree for a large portion of the patients amid hospitalization course and had been recorded in their therapeutic diagrams. In view of the patients' standard dietary measurements, a metabolic bolster's arrangement for liquids, calories, protein, fat, and starch ought to be intended for every patient. ${ }^{13}$ We have utilized ASPEN criteria for assessment of PN in the study. Roughly $21.1 \%$ of the patients got calorie objectives, yet we have not found any big relationship between's the patients' calorie admission and mortality. However sample size of the study was too little for assessment of relationships between the parameters. $80 \%$ of the patients got adequate liquid (volume) and it appears that low calorie admission was not because of inadequate intake of volume. Electrolytes, vitamins, minerals and other follow components are fundamental part of $\mathrm{PN}$ and metabolic complications can emerge taking after inappropriate replacement of these nutrients. ${ }^{11,13}$ From these components, calcium was frequently replaced and inappropriately for the patients. Adequate calcium substitution is essential as there is a significant urine calcium loss in patients who receiving $\mathrm{PN} .{ }^{14,15}$

\section{CONCLUSION}

PN feeding does not appear to offer beneficial advantage in rates of complications and it doesn't seem to diminish the length of hospital stay. TPN instantly taking after major surgery is a reasonable parenteral feeding.

Copyright@ 05 Jan, 2017.

\section{REFERENCES}

1. Tjeertes EK, Hoeks SE, Beks SB, Valentijn TM, Hoofwijk AG, Stolker RJ. Obesity--a risk factor for postoperative complications in general surgery? BMC Anesthesiol 2015 Jul 31; 15:112.

2. Mueller C, Compher C, Ellen DM, American Society for Parenteral and Enteral Nutrition (A.S.P.E.N.) Board of Directors. A.S.P.E.N. clinical guidelines: nutrition screening, assessment, and intervention in adults. JPEN J Parenter Enteral Nutr 2011; 35(1):16-24.

3. Shang E, Hasenberg T, Sclegel B, Sterchi AB, Schindler $\mathrm{K}$, Druml W, et al. An European survey of structure and 
organization of nutrition support teams in Germany, Austria and Switzerland. Clin Nutr 2005; 24:1005-13.

4. Dempsey DT, Mullen JL, Buzby GP. The link between nutritional status and clinical outcome: can nutritional intervention modify it? Am J Clin Nutr 1988; 47:352-6.

5. McWhirter JP, Pennington CR. Incidence and recognition of malnutrition in hospital. $\mathrm{Br}$ Med $\mathrm{J}$ 1994; 308:945-8.

6. Souba WW, Wilmore D. Diet and nutrition in the care of the patient with surgery, trauma, and sepsis. In: Shils M, Olson J, Shike M, Ross AC, editors. Modern nutrition in health and disease. 9th ed. Baltimore, MD: Williams \& Wilkins; 1999. p. 1589-618.

7. Green CJ. The role of peri-operative feeding. S Afr Med J 1998; 88:92-8.

8. Macfarlane K, Bullock L, Fitzgerald JF. A usage evaluation of total parenteral nutrition in pediatric patients. J Parenter Enteral Nut 1991; 15:85-88.

9. Gallagher B, Allred CR, Voss AC: Malnutrition and clinical outcomes; the case of medical nutrition therapy. J Am Diet Assoc 1996; 96:361-66.

10. Kim DY, Lee SM, Lee KE, Lee HR, Kim JH, Lee KW, et al. An evaluation of nutrition support for terminal cancer patients at teaching hospitals in Korea. Cancer Res Treat 2006; 38:214-17.

11. Font-Noguera I, Cercós-Lletí AC, Llopis-Salvia P. Quality improvement in parenteral nutrition care. Clin Nutr 2001; 20:83-91.

12. Gales BJ, Riley DG. Improved total parenteral nutrition therapy management by a nutritional support team. Hosp Pharm 1994; 29:469-70.

13. Sacks GS, Rough S, Kudsk KA. Frequency and severity of harm of medication errors related to the parenteral nutrition process in a large university teaching hospital. Pharmacotherapy 2009; 29:966-74.

14. Ribeiro DO, Lobo BW, Volpato NM, Veiga VF, Cabral LM, Sousa VP. Influence of the calcium concentration in the presence of organic phosphorus on the physicochemical compatibility and stability of all-inone admixtures for neonatal use. Nutr J 2009; 8:1-13.

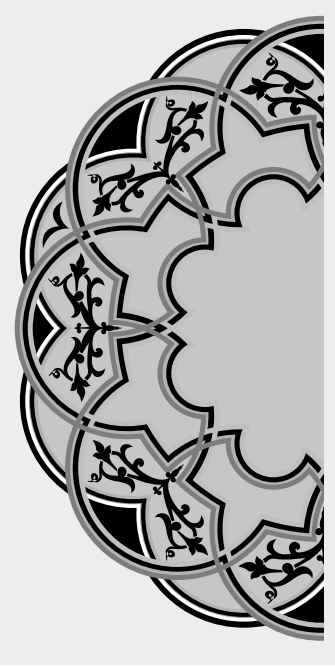

"Success is a lousy teacher, It seduces smart people into thinking they can't lose."

\author{
Bill Gates
}

\title{
AUTHORSHIP AND CONTRIBUTION DECLARATION
}

\begin{tabular}{|c|c|c|c|}
\hline Sr. \# & Author-s Full Name & Contribution to the paper & $\begin{array}{l}\text { Author }=\mathbf{s} \\
\text { Signature }\end{array}$ \\
\hline 1 & Dr. Muzaffar Aziz & Principal Author & to $A$ \\
\hline 2 & Dr. Tariq Jamil Choudhary & Co-author & 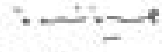 \\
\hline 3 & Dr. Muhammad Shafiq & Co-author & \\
\hline 4 & Dr. Khalid Hussain Qureshi & Co-author & \\
\hline
\end{tabular}

